\title{
Evaluation of a Communication Campaign To Improve Continuation Among First-Time Injectable Contraceptive Users in Nyando District, Kenya
}

By Holly McClain Burke and Constance Ambasa-Shisanya

Holly McClain Burke is scientist, FHI 360, Durham, NC, USA. Constance AmbasaShisanya is research associate, Exceed Consultancy Services, Nairobi, Kenya.
CONTEXT: Communication campaigns might be a viable means of improving contraceptive continuation; however, few such interventions aimed at reducing contraceptive discontinuation have been evaluated.

METHODS: Data were collected from independent samples of new injectable users in Nyando District, Kenya-site of a communication campaign to increase contraceptive continuation-and in a comparison district, nine months before and nine months after intervention implementation. Survival analysis was used to compare the intervention and comparison groups with respect to the distribution of time until first discontinuation of modern method use among women still in need of family planning.

RESULTS: Exposure to family planning information was high in both the treatment and the comparison district before (97\% and $85 \%$, respectively) and after the intervention (99\% and $78 \%$ ). Postintervention, $5 \%$ of women in the comparison district discontinued by 98 days, $8 \%$ by 196 days and $23 \%$ by 294 days; the proportions in the treatment district were $4 \%, 6 \%$ and $16 \%$, respectively. No significant difference between the districts was found in the ninemonth postintervention contraceptive continuation rates. Having method-related side effects or health concerns was the reason most consistently associated with discontinuation. Other factors associated with discontinuation differed between the districts.

CONCLUSIONS: Addressing method-related side effects and health concerns will be critical in improving continuation of the injectable.

International Perspectives on Sexual and Reproductive Health, 2014, 40(2):56-67; doi: 10.1363/4005614
Consistent and correct contraceptive use is necessary for women who want to limit their family size. Unfortunately, many women who wish to space or stop childbearing discontinue contraceptive use. Variables consistently associated with contraceptive discontinuation include method type, side effects, age, number of living children, fertility intentions and change in marital status. ${ }^{1}$ Other measures linked to discontinuation-although not consistently across studies-include number of methods available, ${ }^{2}$ socioeconomic factors, ${ }^{1,3,4}$ urban-rural residence, ${ }^{3}$ husband's disapproval of contraceptive use $e^{5}$ and cost of or access to methods. ${ }^{2,4}$ Studies have shown that quality of family planning services affects discontinuation, although such results have not been strong or consistent. ${ }^{2,6-8}$

Sustained method use is particularly problematic among users of the injectable contraceptive. ${ }^{9}$ In Kenya, the injectable is the most popular method-used by $22 \%$ of married women in 2009; however, 29\% discontinued use within 12 months of starting. Issues related to side effects are a major reason for women's discontinuation of the injectable.

To date, few interventions aimed at reducing contraceptive discontinuation have been evaluated; those that have have focused on improving counseling, and their assessments have yielded mixed results. ${ }^{10-15}$ Communication campaigns, which deliver messages repetitively, have been associated with increased adoption of contraceptive use, ${ }^{16-21}$ in these studies, radio was an important channel of message delivery. Such campaigns may be a viable means of improving method continuation.

In this study, we developed and evaluated a communication campaign to increase contraceptive continuation rates among first-time injectable users in Nyando District, Kenya.

\section{Theoretical Model}

Our model for predicting contraceptive continuation expands on the Bruce-Jain framework ${ }^{22}$ and has been described elsewhere. ${ }^{23}$ The Bruce-Jain framework links quality of family planning services to fertility through contraceptive prevalence, acceptance and continuation. It outlines six elements of service quality: choice of methods, information given to clients, provider competence, client-provider relations, follow-up and continuity mechanisms, and appropriate constellation of services. Quality of services is primarily considered a supply factor. Demand factors, including fertility motivations, also influence continuation. Couples' desire or motivation to regulate their fertility is considered the most important factor affecting demand for contraception.

We expanded on the Bruce-Jain framework by adding constructs from the theories of reasoned action and planned behavior. ${ }^{24,25}$ The theory of reasoned action was 
developed to understand the relationship between attitudes and behaviors. ${ }^{24}$ According to this theory, the most important predictor of behavior is intention, which is influenced by attitudes and subjective norms associated with the behavior. Subjective norms are influenced by an individual's perception of the attitudes of important referents toward the behavior and motivation to comply with those referents. In this study, the salient referents are those influencing women's contraceptive behavior (i.e., family members, service providers).

The theory of planned behavior contributed the construct of perceived behavioral control to reasoned action, to account for factors outside the individual's control that may influence intention and behavior. In the context of this study, contraceptive users' beliefs about continuing method use should be determined and addressed for behavior change to occur. Specifically, beliefs that inhibit the desired behavior should be countered and those that encourage the behavior should be supported.

On this theoretical basis, we included in our model perceived side effects and health concerns held by contraceptive users and salient referents. Although Jain acknowledges that contraceptive users should be informed about side effects, ${ }^{22}$ the provision of such information during a brief counseling session may not change their beliefs, which are often deeply entrenched in and reinforced by cultural norms. Moreover, Jain's concept of "information to users" includes only information about side effects found to be significant in clinical studies, not that related to the beliefs or fears contraceptive users may actually have about methods. According to reasoned action and planned behavior, failure to address users' perceived side effects and health concerns-even if erroneous-will thwart behavior change.

According to the theories of reasoned action and planned behavior, salient referents and their beliefs about users continuing to use a method should be incorporated into interventions to increase continuation. A qualitative study in four developing countries recommends that contraceptive interventions involve the user's husband, friends and family members. ${ }^{26}$ Women reported that these referents influence their decision to use, continue using and remove a contraceptive implant. In two of the countries studied, mothers and mothers-in-law were especially influential in decisions affecting fertility, and expressed the most resistance to the method and worry about side effects.

\section{METHODS}

\section{Communication Campaign}

-Development. Formative research informed the development of a communication campaign addressing community-specific concerns and targeting contraceptive users and salient referents in Nyando District. ${ }^{27}$ Nyando was selected because of its location in Nyanza Province, which has a 15\% HIV prevalence rate-double the national average. ${ }^{28}$ This high HIV prevalence has led to an increased focus on improving reproductive health services in the region, because preventing unintended pregnancies among women with HIV is an effective HIV prevention strategy. ${ }^{29,30}$

Common reasons for contraceptive discontinuation in Nyando include side effects; husbands' opposition to contraception; provider or clinic restrictions, such as menstruation requirements; misconceptions about the injectable; stock-outs; and cost. ${ }^{27}$ We used these reasons to develop community-specific messages for the campaign. Radio was chosen as the main delivery method, given its potential to influence millions of Kenyan women; $74 \%$ percent of Kenyan households have a radio, and $81 \%$ of women in Nyanza Province listen to the radio at least weekly. ${ }^{9}$

- Radio spots. We developed six radio spots-each targeting a specific group: new or current injectable users, husbands, mothers-in-law, family planning providers, community leaders and long-term injectable users. For example, the spot targeting community leaders focused on how family planning can reduce the burden on community resources and attempted to dispel misconceptions about the injectable. The spot targeting husbands emphasized that the injectable is safe, but may cause side effects; it recommended that couples who find the side effects unacceptable should visit their provider for more information or to switch methods.

All radio spots aired daily, from April to December 2009, prior to the prime news on Radio Ramogi; an independent company monitored the spots to ensure that they aired as intended. Three radio spots (targeting current users, husbands and mothers-in-law) aired 60 times in July 2009 on another local station, Radio Nam Lolwe. In addition, in May 2009, three live radio shows aired on Radio Nam Lolwe to increase knowledge and correct misconceptions about family planning; listeners could call in to ask the show's guest (e.g., a family planning expert or a current contraceptive user) questions.

- Other components. Print materials-such as a brochure for injectable users and posters aimed at women and their husbands-were developed to complement the radio campaign. These materials were distributed to family planning clinics in Nyando District in March 2009; posters targeting men were displayed in locations frequented by men, such as community gathering spots. Finally, in March 2009, 195 community health workers in Nyando were trained to counsel clients about and refer them for the injectable.

\section{Study Evaluation}

- Design. We used an untreated comparison group design with independent pretest and posttest samples to evaluate the intervention. ${ }^{31}$ We selected Mumias District as the comparison site, because it is located in Western Province, which borders Nyanza to the north, but does not share the local radio stations used for the intervention. Mumias has an HIV prevalence rate similar to the national average. ${ }^{28}$

Data on continuation rates in the treatment and comparison sites were collected before and after campaign implementation. Following an intent-to-treat approach, we considered all participants in Nyando exposed to the 
intervention and all participants in Mumias not exposed, regardless of their reported exposure. This study protocol was approved by Kenyatta National Hospital's Ethics and Research Committee in Nairobi, Kenya, and FHI 360's Protection of Human Subjects Committee.

- Sample enrollment. Sample size was based on application of survival analysis. We calculated that a one-sided, log-rank test with an overall sample size of 912 participants (456 in the intervention district and 456 in the comparison district) would provide $90 \%$ power at a .05 significance level to detect a difference between districts assuming, on the basis of Demographic and Health Survey (DHS) data, that $70 \%$ of the intervention group and $60 \%$ of the comparison group would not discontinue method use within nine months. We assumed 15\% of participants would be lost to follow-up. We aimed to enroll at least 500 participants from each district in each time period, to allow for potential clustering effects arising from participants recruited from the same clinics.

We identified clinics with the highest average number of injectable clients (new and returning) from a list of all Ministry of Health clinics that provide the injectable in each study district. For the preintervention period, we selected a random sample of 10 of those clinics from each district. The same clinics were used for the postintervention period, although three in Nyando and two in Mumias were inaccessible due to heavy rains and were replaced with others randomly selected from the original list.

Women who attended a study clinic during the two enrollment periods (April-June 2008 for preintervention and April-June 2009 for postintervention) were screened for eligibility. Those who were initiating use of depot medroxyprogesterone acetate (DMPA) for the first time, aged 18 or older and living in one of the study districts, and who gave written consent, were eligible. Participants were interviewed at baseline (after receiving their first DMPA injection) and then reinterviewed every three months for nine months. At each assessment, a trained female research assistant administered a quantitative questionnaire measuring demographic characteristics, contraceptive use and variables that may influence contraceptive continuation.

-Preintervention sample. We recruited 505 women for the preintervention treatment group and 501 for the comparison group. We excluded 71 women from Nyando and 65 from Mumias because they lacked follow-up data; an additional three women in Nyando were excluded because they lacked baseline data. No differences in baseline variables were found between those in the comparison group who lacked follow-up data and those who remained. In the treatment group, those excluded were younger, less likely to have a secondary or higher education and more likely to want to space rather than limit their childbearing. After exclusions, the final preintervention treatment group con-

*Following the definition used by the DHS, we considered modern methods to include male or female sterilization, the IUD, the implant, the injectable, oral contraceptive pills, male or female condoms, diaphragm and spermicides, and the lactational amenorrhea method. sisted of 431 participants, who contributed 876 records, and the final preintervention comparison group consisted of 436 participants, who contributed 970 records.

Two percent of women in each group switched from the injectable to another modern method during the preintervention period. Eight percent of the treatment group and $15 \%$ of the comparison group discontinued modernmethod use while still in need of family planning. The average number of days of continuous modern method use during the preintervention period was 201 in Nyando and 212 in Mumias.

Fifty-eight percent of the treatment group and 37\% of the comparison group were lost to follow-up in the preintervention period before we could measure discontinuation. The pattern of loss differed between the groups: Thirty-five percent of those lost in Nyando were lost after the first follow-up interview, compared with $21 \%$ in $\mathrm{Mu}$ mias. In both sites, those lost were more likely than those who remained to be from urban areas; in addition, those lost from Nyando reported a greater number of methods discussed by the provider during enrollment, and those lost from Mumias were younger.

- Postintervention sample. We recruited 523 women for the postintervention treatment group and 531 women for the comparison group. We excluded 11 women from Nyando and 13 from Mumias because they lacked follow-up data. In both districts, those excluded were more likely than those who remained to say their husband disapproved of family planning. The final postintervention treatment group consisted of 512 women, who contributed 1,436 records; the final postintervention comparison group consisted of 518 women, who contributed 1,433 records.

Four percent of women in the treatment group and $2 \%$ of women in the comparison group switched from the injectable to another modern method during the postintervention period. The proportion who discontinued modern method use although still in need of family planning was 3\% in the treatment group and 4\% in the comparison group. The average number of days of continuous modern method use during the postintervention period was 260 in Nyando and 254 in Mumias.

Six percent of the treatment group and $7 \%$ of the comparison group were lost to follow-up postintervention before we could measure discontinuation. In both districts, those lost had fewer living children than those who remained. In Nyando, those lost to follow-up were more likely to be younger and urban, and less likely want no more children; in Mumias, those lost to follow-up planned to use injectables for a shorter time.

- Dependent variable. Our primary outcome was time to first discontinuation of modern method use among women still in need of family planning. At each followup, participants were asked about their contraceptive use. Women who reported continued use of the injectable or switching to any other modern method* were considered "continuers." Those who reported not continuing injectable use and not switching to another modern method 
were asked why they had discontinued. We used women's reasons to divide them into two groups: those no longer in need of family planning and those still in need. On the basis of standard DHS definitions, reasons associated with women being still in need included pregnancy while using a method (method failure); partner disapproval of contraception; health concerns; side effects; lack of access; expense; inconvenience; and desire for a more effective method (among women who did not switch to another modern method). Participants who discontinued while still in need were considered to have experienced an event in the survival models. Women were censored at the point at which they were lost to follow-up, discontinued from the study or were considered to no longer be in need.

At the time of the study, DMPA reinjection was every three months, and family planning protocols in Kenya allowed reinjections as late as 14 weeks or 98 days after the previous injection. ${ }^{32}$ The duration of modern method use in the study was calculated using the lowest of the following values: number of days between date of last interview and enrollment date; number of days covered by a modern method; or 294 days, which is the maximum number of days covered by a modern method during the study (based on 98 days of protection from one DMPA injection multiplied by three follow-up interviews).

-Independent variables. We included independent variables taken from the DHS or created specifically to measure constructs suggested by our theoretical model. Respondents provided answers to some items only at baseline (time-independent variables), and to others at baseline and up to three follow-up interviews (time-dependent variables); to accommodate the time-dependent covariates, we structured the data using the counting process form of a Cox model. ${ }^{33}$

Preintervention exposure to family planning information was based on women's responses to four questions asking whether, in the last three months, they had seen or heard advertisements or information about various health topics on the radio; on the television; during a theater performance; or on a billboard, poster or pamphlet. Health topics included alcohol use, birthspacing, continuation of a family planning method, domestic violence, family planning, HIV and AIDS, malaria, nutrition and oral rehydration for children. Women were considered to have been exposed to family planning information if they reported any exposure to information about birthspacing, continuation of a family planning method or family planning. In addition, we constructed a continuous variable of the number and types of health messages to which respondents reported having been exposed, ranging from 0 to 12 .

A measure of postintervention exposure to family planning information was constructed similarly, although the possible health topics were expanded to include family planning injections, male involvement, side effects of the injections, and vaccinations for children. Women were considered to have had postintervention exposure to family planning information if they reported any exposure to information about birthspacing, continuation of a family planning method, family planning, family planning injections, male involvement in family planning or side effects of the injectable contraceptive. Respondents were also considered to have had exposure to family planning information if they answered "yes" to any of three questions on whether they, at last clinic visit, had seen a poster about the side effects of the injectable or a brochure about the injectable, or in the previous three months had discussed any method-related health concerns or side effects with friends, neighbors, relatives or community-based health workers. In addition, we constructed a continuous variable of the number and types of health messages to which respondents had reported having been exposed, ranging from 0 to 27.

We created dichotomous measures of ethnicity (dominant ethnic group vs. other) and religion (Christian vs. other), because the vast majority of respondents were members of their district's predominant ethnic group (Luo in Nyando, and Luhya in Mumias) and were Christian. In addition, a dichotomous urban-rural residence variable was based on participants' response to the question "Where do you currently live?"; the name of the town or neighborhood was recorded verbatim, and urbanrural residence was determined with the assistance of incountry field staff. Education was a categorical measure (none, primary, or secondary or higher). We measured income with a continuous variable based on the question "How much household income does your household receive each month, counting all sources?"; the measure was log-transformed to rescale it, so it would not overwhelm the survival analysis model.

Baseline marital status was measured with a yes or no question, and a dichotomous measure of change in marital status was constructed by comparing women's responses at consecutive interviews. Women were asked how many living children they had. Women's fertility intentions were determined by asking, "Would you like to have (a/another) child, or would you prefer not to have any (more) children?" Women who wanted a child or another child were asked how long they would like to wait; responses were dichotomized to two years or less and more than two years.

We included various family planning measures. Dichotomous variables measured whether women at baseline reported having previously used a modern contraceptive method or thought that their partner approved of using a contraceptive method, and whether women at followup had experienced a side effect or had a health concern while using the injectable. Women were asked, "Since your last interview approximately three months ago, have you experienced any side effects or problems while using injectables?" Those who answered affirmatively were asked to pick from a list all of the side effects or problems they had experienced; we constructed a continuous variable by summing the number of unique issues mentioned. We included a dichotomous variable that measured whether women had any fear of side effects or other health con- 
cerns regarding method use; any concerns mentioned were considered valid, including those not found in the medical literature. A dichotomous variable measured whether women had experienced a problem obtaining the injectable. Respondents were considered to have had an access problem if they reported that the injectable was difficult or impossible to obtain when asked "What side effects or problems did you experience using injectables?" during the interview when a discontinuation was reported, or if they reported "yes" to the question "Did you come more than once to get your most recent family planning appointment?" Women were asked how long they planned to continue to use the injectable; responses were converted into days. Cost of family planning services was measured by summing the amounts women reported paying for services at their most recent family planning appointment and for one-way transportation to that appointment.

In addition, three separate exploratory factor analyses were conducted in Mplus 5.2 to create independent variables for the survival models; standard factor analysis methods were used. ${ }^{34,35}$ The aim of the first was to construct time-dependent measures of motivations to avoid pregnancy. Nineteen variables were entered into the analysis based on face validity. We included a baseline measure of the number of days participants planned to use the injectable. A variable measuring current fertility intentions was based on how long respondents reported wanting to wait before having a child; response options included "2 years or less," "more than 2 years" and "no more children." Partner's fertility intentions were measured with the question, "Does your husband/partner want to have another child within two years?" Response options were "yes," "no" and "don't know"; a dichotomous variable was constructed combining "don't know" and "yes" responses. We included a measure of how problematic women thought a hypothetical pregnancy in the next few weeks would be. Response options were "big problem," "small problem" and "no problem"; "don't know" responses were included in the "small problem" category. Respondents were asked their level of confidence in using contraceptives to avoid pregnancy; response options were "very confident," "somewhat confident" and "not very confident." Women's attitudes toward contraception and pregnancy were measured by their agreement to 14 statements, such as "my husband/partner expects me to use contraception" and "I am nervous about using contraception." Response options were "strongly agree," "moderately agree," "neither agree or disagree," "moderately disagree" and "strongly disagree." Two factors were retained, with 15 variables total; the first factor was interpreted as measuring the couple's motivation to avoid pregnancy, and the second was interpreted as measuring perceived family support of contraceptive use.

The second exploratory factor analysis aimed to construct time-dependent measures of decision-making power regarding contraceptive use and health care; six variables were entered on the basis of face validity. A variable of family planning self-determination was based on the question, "Would you say that using family planning is mainly your decision, mainly your husband's/partner's decision or did you both decide together?" Response options were respondent, joint decision, husband or other person; "don't know" responses were combined into one category with husband and other. Women were asked whether they had talked to their partner about family planning "never," "once or twice" or "more often" in the past three months. A variable measured women's perceptions of whether their partner desired more, the same number of or fewer children than they did. The respondent's empowerment was measured by the question, "In general, if you disagree with your husband/partner, should you keep quiet or speak up?" A variable measuring health care self-determination was based on the question, "Who usually makes decisions about your health care?" Response options were respondent, joint decision, husband or other person; women who answered "don't know" were combined into one category with those who answered "husband" or "other." Women were asked who in the family has the ultimate say about the number of children to have, which was coded the same as the variable for health care self-determination. All six variables were retained and contributed to the one-factor solution interpreted as measuring empowered decision making about the woman's health.

The third exploratory factor analysis aimed to construct time-dependent measures of perceived quality of care at women's last family planning appointment; 21 variables were entered on the basis of face validity. Women were asked which family planning methods their provider discussed during the visit. A dichotomous measure of whether women had received their method of choice was created by asking at each interview what method they wanted when they came to their most recent appointment and which method they received. Women were coded as having received their method of choice if their answers to the two questions were the same; those who had no method preference were coded as having received their method of choice. Chosen method availability was a dichotomous measure based on the question, "Why didn't you receive the method you wanted to get?"; the chosen method was considered unavailable if respondent answered "clinic did not have my method" or "clinic did not have my brand." Women were asked whether they felt comfortable asking their provider questions or mentioning concerns; women who answered "yes" were considered comfortable and those who answered "somewhat," "no" or "don't know" were considered not comfortable. We included a measure of whether all women's questions had been answered by the provider; responses were dichotomized ("yes" versus "no," "no questions" and "don't know"). Women were asked whether they were satisfied or dissatisfied overall with their care during their visit; "don't know" was combined with "dissatisfied." Satisfaction with provider was measured with the question, "Were you dissatisfied or satisfied with how you were treated by this provider?" Response options were "very satisfied," "somewhat satis- 


\begin{tabular}{|c|c|c|c|c|c|c|c|c|}
\hline \multirow[t]{3}{*}{ Variable } & \multicolumn{4}{|c|}{ Preintervention } & \multicolumn{4}{|c|}{ Postintervention } \\
\hline & \multicolumn{2}{|l|}{$\begin{array}{l}\text { Mumias } \\
(\mathrm{N}=436)\end{array}$} & \multicolumn{2}{|l|}{$\begin{array}{l}\text { Nyando } \\
(\mathrm{N}=431)\end{array}$} & \multicolumn{2}{|l|}{$\begin{array}{l}\text { Mumias } \\
(\mathrm{N}=518)\end{array}$} & \multicolumn{2}{|l|}{$\begin{array}{l}\text { Nyando } \\
(\mathrm{N}=512)\end{array}$} \\
\hline & $\begin{array}{l}\text { Nonmissing } \\
\text { obser- } \\
\text { vations }\end{array}$ & $\begin{array}{l}\text { \%/mean } \\
\text { (sd) }\end{array}$ & $\begin{array}{l}\text { Nonmissing } \\
\text { obser- } \\
\text { vations }\end{array}$ & $\begin{array}{l}\% / \text { mean } \\
\text { (sd) }\end{array}$ & $\begin{array}{l}\text { Nonmissing } \\
\text { obser- } \\
\text { vations }\end{array}$ & $\begin{array}{l}\% / \text { mean } \\
\text { (sd) }\end{array}$ & $\begin{array}{l}\text { Nonmissing } \\
\text { obser- } \\
\text { vations }\end{array}$ & $\begin{array}{l}\text { \%/mean } \\
\text { (sd) }\end{array}$ \\
\hline \multicolumn{9}{|l|}{ PERCENTAGES } \\
\hline $\begin{array}{l}\text { Urban residence } \\
\text { Ethnicity }\end{array}$ & 436 & 41 & 430 & 29 & 518 & 28 & 512 & 25 \\
\hline Luhya & 434 & 92 & na & na & 518 & 87 & na & na \\
\hline Luo & na & na & 430 & 90 & na & na & 512 & 93 \\
\hline \multicolumn{9}{|l|}{ Education } \\
\hline Primary & 436 & 67 & 423 & 59 & 518 & 79 & 512 & 78 \\
\hline$\geq$ secondary & 436 & 24 & 423 & 38 & 518 & 12 & 512 & 20 \\
\hline Christian & 434 & 86 & 428 & 98 & 518 & 86 & 512 & 100 \\
\hline Married & 434 & 89 & 428 & 88 & 518 & 92 & 512 & 88 \\
\hline Prior modern contraceptive use† & 436 & 22 & 431 & 23 & 518 & 22 & 512 & 29 \\
\hline Does not want any more children & 431 & 27 & 428 & 34 & 518 & 23 & 512 & 27 \\
\hline Husband disapproves of contraceptive use & 422 & 17 & 398 & 21 & 506 & 16 & 497 & 16 \\
\hline \multicolumn{9}{|l|}{ MEANS } \\
\hline Age (range, 18-50) & 436 & $25(6)$ & 431 & $25(6)$ & 518 & $24(5)$ & 512 & $25(5)$ \\
\hline No. of living children (range, $0-12$ ) & 427 & $3(2)$ & 417 & $3(2)$ & 516 & $3(2)$ & 501 & $3(2)$ \\
\hline No. of methods discussed by provider (range, $0-13$ ) & 434 & $4(2)$ & 431 & $4(3)$ & 518 & $2(2)$ & 512 & $3(2)$ \\
\hline \multicolumn{9}{|l|}{ Planned length of injectable use } \\
\hline during enrollment (range, 90-36,135 days) & 390 & $1,577(1,027)$ & 419 & $1,840(2,119)$ & 502 & $1,692(1,426)$ & 499 & $1,995(1,449)$ \\
\hline \multicolumn{9}{|l|}{ Length of continuous use of modern } \\
\hline method during study (range, 82-294 days) & 436 & $212(73)$ & 431 & $201(75)$ & 518 & $254(51)$ & 512 & $260(49)$ \\
\hline
\end{tabular}

fied," "neither," "somewhat unsatisfied" and "unsatisfied"; we combined "neither," "somewhat unsatisfied," "unsatisfied" and "don't know" because of low frequencies. The question "How satisfied were you with the level of cleanliness at the facility?" used the same response options and categorization as the question on provider satisfaction. A dichotomous variable measured whether women had enough privacy at the clinic. The question "Where do you think you will go for your next family planning appointment?" measured women's willingness to return to the clinic; responses mentioning the same facility were coded "yes," and all others were coded "no." Seven dichotomous variables assessed whether providers gave women specific method-related information, such as advantages or disadvantages, and possible side effects or problems. We asked women if the provider had asked if they had prior experience with contraceptives and what method they preferred. Two continuous variables measured (in minutes) women's travel time to and their waiting time at the clinic at their most recent family planning visit; both variables were log-transformed to rescale to avoid overwhelming the factor analysis model. A single factor was retained with eight variables and interpreted to measure information about the family planning method given to women by their provider.

\section{Data Analysis}

Analysis was conducted using SAS 9.2. Household income was omitted, because data were missing for more than $20 \%$ of participants in both districts. We used multiple im- putation to handle missing data for independent variables using the Markov chain Monte Carlo method with a single chain to create five imputations. ${ }^{36}$ Unless otherwise noted, $\mathrm{p}<.05$ was considered statistically significant.

We evaluated time to first discontinuation among women still in need of family planning by fitting pre- and postintervention data from both districts in a single Cox model with terms for treatment (or district), timing (pre- vs. postintervention), and the interaction between treatment and timing. We specified a linear contrast of the model parameters to test whether discontinuation rates differed between the districts when the model was adjusted for differences in preintervention discontinuation rates.

Factors associated with discontinuation were identified using Cox regression models fit separately for each district and period. We used the exact likelihood method to handle tied event times, which are expected in these data. To control for clustering expected at the clinic level, we used a sandwich estimator to obtain robust standard errors.

In bivariate analyses, we examined whether each independent variable was associated with discontinuation; these analyses were conducted separately for each district and period. Only independent variables found significant in either district $(\mathrm{p}<0.20)$ and those hypothesized to predict discontinuation (age, number of children, fertility intentions and change in marital status) were entered into the model to predict time to first discontinuation. Backward model reduction was then used to eliminate nonsignificant variables to arrive at a final model; a level of $p<.10$ 
was used to determine significance. ${ }^{37}$

Using a log-rank test, we compared the two study districts with respect to the distribution of time to discontinuation. We used only postintervention data to identify the predictors and rates of discontinuation, because of the high and differential loss to follow-up before the intervention-the result of a contractual dispute that was resolved prior to the postintervention period. Loss to follow-up after the intervention was lower than expected.

\section{RESULTS}

\section{Descriptive Statistics}

At baseline, in both the pre- and postintervention samples, most women (86-100\%) were members of their district's majority ethnic group, Christian and married (Table 1, page 61). About one-quarter (22-29\%) had used a modern method other than the injectable prior to enrollment.
On average, women had three living children; 23-34\% reported not wanting any more children.

For survey items to which women responded multiple times (i.e, at baseline and follow-ups), we used survey records as the unit of analysis (Table 2). In 30-39\% of records, women reported experiencing at least one injectable-related side effect or health concern. The preintervention proportions of records in which women expressed fear of side effects were 42\% in Mumias and 33\% in Nyando; the proportions postintervention were $26 \%$ and $18 \%$, respectively. The proportions of records in which women reported having difficulty accessing the injectable were $13-16 \%$ preintervention and 5-7\% postintervention. In virtually all records (95-99\%), women reported receiving their method of choice. In $31-33 \%$ of postintervention records, women reported that their provider gave them information about possible method-related side effects

TABLE 2. Descriptive statistics of survey records contributed by women initiating use of the injectable, by selected timedependent variables, according to survey time and district

Variable

\begin{tabular}{|c|c|c|c|c|c|c|c|}
\hline \multicolumn{4}{|c|}{ Preintervention } & \multicolumn{4}{|c|}{ Postintervention } \\
\hline \multicolumn{2}{|l|}{$\begin{array}{l}\text { Mumias } \\
(\mathrm{N}=970)\end{array}$} & \multicolumn{2}{|l|}{$\begin{array}{l}\text { Nyando } \\
(\mathrm{N}=876)\end{array}$} & \multicolumn{2}{|c|}{$\begin{array}{l}\text { Mumias } \\
(\mathrm{N}=1,433)\end{array}$} & \multicolumn{2}{|c|}{$\begin{array}{l}\text { Nyando } \\
(\mathrm{N}=1,436)\end{array}$} \\
\hline $\begin{array}{l}\text { Non- } \\
\text { missing } \\
\text { obser- } \\
\text { vations }\end{array}$ & $\begin{array}{l}\% / \\
\text { mean } \\
\text { (sd) }\end{array}$ & $\begin{array}{l}\text { Non- } \\
\text { missing } \\
\text { obser- } \\
\text { vations }\end{array}$ & $\begin{array}{l}\% / \\
\text { mean } \\
\text { (sd) }\end{array}$ & $\begin{array}{l}\text { Non- } \\
\text { missing } \\
\text { obser- } \\
\text { vations }\end{array}$ & $\begin{array}{l}\% / \\
\text { mean } \\
\text { (sd) }\end{array}$ & $\begin{array}{l}\text { Non- } \\
\text { missing } \\
\text { obser- } \\
\text { vations }\end{array}$ & $\begin{array}{l}\% / \\
\text { mean } \\
\text { (sd) }\end{array}$ \\
\hline 968 & 7 & 873 & 4 & 1,433 & 3 & 1,436 & 2 \\
\hline 970 & 1 & 876 & 1 & 1,433 & 1 & 1,436 & 2 \\
\hline 956 & 39 & 868 & 30 & 1,433 & 32 & 1,436 & 39 \\
\hline 841 & 42 & 729 & 33 & 1,408 & 26 & 1,429 & 18 \\
\hline 945 & 86 & 868 & 88 & 1,431 & 87 & 1,435 & 95 \\
\hline 956 & 97 & 875 & 93 & 1,433 & 97 & 1,436 & 99.7 \\
\hline 858 & 16 & 826 & 13 & 1,366 & 19 & 1,419 & 11 \\
\hline 858 & 56 & 826 & 53 & 1,366 & 60 & 1,419 & 63 \\
\hline 872 & 16 & 778 & 13 & 1,412 & 5 & 1,430 & 7 \\
\hline 838 & 99 & 730 & 97 & 1,409 & 99 & 1,429 & 99 \\
\hline 838 & 98 & 730 & 95 & 1,409 & 99 & 1,429 & 98 \\
\hline 849 & 54 & 729 & 55 & 1,409 & 31 & 1,429 & 33 \\
\hline 840 & 50 & 725 & 83 & 1,409 & 48 & 1,425 & 94 \\
\hline 810 & 84 & 725 & 89 & 1,408 & 87 & 1,427 & 94 \\
\hline 831 & 57 & 727 & 64 & 1,408 & 32 & 1,428 & 40 \\
\hline 835 & 92 & 725 & 97 & 1,409 & 97 & 1,428 & 99 \\
\hline 839 & 86 & 727 & 95 & 1,409 & 79 & 1,429 & 91 \\
\hline 852 & 83 & 731 & 89 & 1,409 & 78 & 1,429 & 87 \\
\hline 849 & 99 & 722 & 98 & 1,406 & 98 & 1,425 & 96 \\
\hline 956 & $1(1)$ & 868 & $1(1)$ & 1,433 & $1(1)$ & 1,436 & $1(1)$ \\
\hline 855 & $53(25)$ & 731 & $42(47)$ & 1,409 & $52(28)$ & 1,429 & $42(35)$ \\
\hline 827 & $50(70)$ & 722 & $60(121)$ & 1,407 & $45(56)$ & 1,425 & $51(73)$ \\
\hline 803 & 35 (44) & 721 & $43(103)$ & 1,409 & $39(50)$ & 1,427 & $36(65)$ \\
\hline
\end{tabular}

PERCENTAGES

Change in marital status

Switched to another modern method during study

\section{Contraception}

Experienced $\geq 1$ injectable-related side effect/health concern

Fear of method-related side effect/health concern

Very confident in using contraceptives

to avoid pregnancy

Strongly agrees that using contraceptive allows for better care of family

Fertility intentions

Wants a child in $\leq 2$ years

Wants a child in $>2$ years

Perceived quality of care

Problem accessing injectable

Method of choice was available

Received method of choice

Provider gave information about possible method-related side effects/problems

Enough privacy during visit

Comfortable discussing questions/ concerns with provider

Provider answered all method questions

Overall satisfied with care

Very satisfied with provider

Very satisfied with facility cleanliness

Would return to the same facility

for next family planning visit

MEANS

No. of side effects/health concerns (range, $0-8$ )

Cost of family planning services (range, $0-800$ shillings)*

Travel time to clinic (range, $1-2,400$ min.) $\dagger$

Waiting time at clinic (range, $0-1,800$ min.) $\dagger$

*Includes transportation one way. The log transformation of these variables was used in the survival models. Notes: Women gave responses for timedependent variables up to four times (baseline and three follow-ups); data were structured using the counting process form of a Cox model. sd=standard deviation. 


\begin{tabular}{|c|c|c|c|c|c|c|c|c|}
\hline \multirow{3}{*}{ Exposure } & \multicolumn{4}{|c|}{ Preintervention } & \multicolumn{4}{|c|}{ Postintervention } \\
\hline & \multicolumn{2}{|l|}{$\begin{array}{l}\text { Mumias } \\
(\mathrm{N}=970)\end{array}$} & \multicolumn{2}{|l|}{$\begin{array}{l}\text { Nyando } \\
(\mathrm{N}=876)\end{array}$} & \multicolumn{2}{|l|}{$\begin{array}{l}\text { Mumias } \\
(\mathrm{N}=1,433)\end{array}$} & \multicolumn{2}{|l|}{$\begin{array}{l}\text { Nyando } \\
(\mathrm{N}=1,436)\end{array}$} \\
\hline & $\begin{array}{l}\text { Nonmissing } \\
\text { observations }\end{array}$ & $\begin{array}{l}\% / \\
\text { mean } \\
(\mathrm{sd})\end{array}$ & $\begin{array}{l}\text { Nonmissing } \\
\text { observations }\end{array}$ & $\begin{array}{l}\% / \\
\text { mean } \\
\text { (sd) }\end{array}$ & $\begin{array}{l}\text { Nonmissing } \\
\text { observations }\end{array}$ & $\begin{array}{l}\% / \\
\text { mean } \\
(\mathrm{sd})\end{array}$ & $\begin{array}{l}\text { Nonmissing } \\
\text { observations }\end{array}$ & $\begin{array}{l}\% / \\
\text { mean } \\
(\mathrm{sd})\end{array}$ \\
\hline \multicolumn{9}{|l|}{ PERCENTAGES } \\
\hline$\geq 1$ family planning message & 881 & 85 & 826 & 97 & 1,433 & 60 & 1,436 & 98 \\
\hline $\begin{array}{l}\geq 1 \text { family planning message, including intervention components } \\
\text { Poster about side effects of the injectable during }\end{array}$ & na & na & na & na & 1,433 & 78 & 1,436 & 99 \\
\hline most recent family planning visit & na & na & na & na & 1,400 & 13 & 1,423 & 89 \\
\hline $\begin{array}{l}\text { Brochure about the injectable during } \\
\text { most recent family planning visit }\end{array}$ & na & na & na & na & 1,409 & $<1$ & 1,429 & 65 \\
\hline \multicolumn{9}{|l|}{ MEANS } \\
\hline $\begin{array}{l}\text { Family planning messages during past } 3 \text { mos. (range, } 0-12 \text { ) } \\
\text { Family planning messages, including intervention }\end{array}$ & 881 & $3(2)$ & 826 & $4(3)$ & 1,433 & $2(2)$ & 1,436 & $6(2)$ \\
\hline components, during past 3 mos. (range, $0-27$ ) & na & na & na & na & 1,433 & $4(4)$ & 1,436 & $13(5)$ \\
\hline
\end{tabular}

or problems; for preintervention records, that proportion was $54-55 \%$. During both periods, a lower proportion of records from women in Mumias than in Nyando showed that women reported having enough privacy during their last family planning appointment and that they were "very satisfied" with their provider. Lower proportions of records from women in Mumias than in Nyando showed that providers answered all of their method-related questions; the proportions of records in which women reported having had all their questions answered were higher during preintervention (57-64\%) than postintervention (32-40\%).

\section{Exposure to Family Planning Information}

Exposure to family planning information was high preand postintervention (Table 3). Before the intervention, women reported exposure to at least one family planning message in $85 \%$ of the records from Mumias and in $97 \%$ from Nyando. On average, women in Mumias had been exposed to three messages during the past three months, and women in Nyando had been exposed to four. Postintervention, the proportion of records in which women reported exposure to family planning messaging (including intervention components) was 78\% in Mumias and 99\% in Nyando. Women in Mumias had been exposed an average of four times and women in Nyando an average of 13 times during the past three months. In 13\% of records from Mumias, women reported exposure to posters; the proportion from Nyando was $89 \%$. Similarly, in fewer than $1 \%$ of records from Mumias, women reported exposure to brochures; the proportion in Nyando was 65\%.

\section{Preintervention Predictors and Rates of Discontinuation}

The first full survival model for each district using preintervention data contained 24 variables associated with discontinuation in bivariate analyses or hypothesized to predict the outcome; after backward model reduction, the final model for each district contained eight variables found significant in one or both districts. In Mumias, the variables predicting discontinuation included number of side effects or health concerns, prior use of a modern method, anxiety about contraceptive use, having had all method questions answered by the provider and sufficiency of privacy during the appointment. In Nyando, the factors predicting discontinuation included number of side effects or health concerns, cost of family planning services, being married at baseline and being satisfied with the provider.

The survival functions for time to contraceptive discontinuation during the preintervention period were different in the two districts (log-rank, $\mathrm{p}=.001$ ). The rate of discontinuation in Nyando rose more slowly than in Mumias. Eight percent of women in Mumias discontinued by 98 days, 14\% by 196 days and 24\% by 294 days; in Nyando, the proportions were 3\%, $7 \%$ and $14 \%$, respectively. Given the high and differing rates of loss to follow-up in the two districts, preintervention sensitivity analyses were conducted, in which women censored during the preintervention period were recoded to discontinue at the time of censoring. ${ }^{38}$ Using this revised definition, the survival functions remained different (log-rank, p=.002); however, discontinuation was slower in Mumias than in Nyando.

\begin{tabular}{|c|c|c|c|c|}
\hline District & $\begin{array}{l}\text { Unadjusted } \\
\text { hazard ratio† }\end{array}$ & $\mathrm{p}$ & $\begin{array}{l}\text { Adjusted } \\
\text { hazard ratiof }\end{array}$ & $\mathrm{p}$ \\
\hline Nyando & $1.01(0.58-1.77)$ & & $1.40(0.76-2.56)$ & \\
\hline Mumias & $0.67(0.28-1.57)$ & 0.42 & $1.20(0.59-2.46)$ & 0.74 \\
\hline
\end{tabular}

tHazard ratio for comparing postintervention to preintervention within district. ¥Model adjusts for district, time, district*time, number of side effects/health concerns reported, cost of family planning services including transportation, prior use of modern contraceptive other than injectable, baseline marital status, being nervous about using contraceptives, satisfaction with provider, having all method questions answered by provider and sufficiency of privacy during visit. 


\begin{tabular}{|c|c|c|}
\hline Variable & Nyando & Mumias \\
\hline No. of side effects/health concerns & $1.86(1.50-2.31)^{* * *}$ & $1.82(1.56-2.13)^{* * *}$ \\
\hline Fear of side effects/health concerns & $1.80(1.15-2.83)^{* *}$ & $0.57(0.31-1.02) \dagger$ \\
\hline Luo ethnicity & $0.38(0.22-0.66)^{* * *}$ & na \\
\hline $\begin{array}{l}\text { Exposure to } \geq 1 \text { family planning continuation } \\
\text { messages, including intervention components }\end{array}$ & $0.13(0.03-0.50)^{* *}$ & $1.75(1.28-2.40)^{* * *}$ \\
\hline $\begin{array}{l}\text { Provider gave information about possible } \\
\text { method-related side effects/problems }\end{array}$ & $3.94(2.17-7.09)^{* * *}$ & na \\
\hline Primary education & $0.25(0.08-0.81)^{*}$ & na \\
\hline zsecondary education & $0.13(0.04-0.39)^{* * *}$ & na \\
\hline
\end{tabular}

\section{Test of Campaign Effects}

To test whether the pace of discontinuation for the two districts changed at different rates over time, we fit preand postintervention data from the two districts together in an unadjusted model, and again in an adjusted model that controlled for differences in preintervention discontinuation rates (Table 4, page 63). Neither model found a difference between districts in the change in the rate of discontinuation pre- and postintervention.

\section{Postintervention Predictors and Rates of Discontinuation}

Using postintervention data, we fit a separate survival model for each district with variables associated with discontinuation in bivariate analyses or hypothesized to predict the outcome. Four categorical variables were eliminated from the selection process because cross-tabulations with the censoring variable revealed an empty cell (e.g., all cases in one category of the variable were censored).

The first models for Nyando and Mumias had 18 and 20 variables, respectively (not shown). After backward model reduction, the final Nyando model contained seven variables and the final Mumias model had three (Table 5). The variable for number of side effects experienced remained in both models (hazard ratios, 1.9 and 1.8, respectively). The variables for fear of side effects and exposure to family planning messaging also remained in both models; however, the former was positively associated with discontinuation in Nyando (1.8) and negatively (and only marginally) associated in Mumias (0.6), whereas the latter was negatively associated with discontinuation in Nyando (0.1) and positively associated in Mumias (1.8). Having received information about method-related side effects was the variable most strongly associated with discontinuation in Nyando (3.9). We found no evidence that the attitudinal or motivational factors developed using factor analytic techniques were associated with discontinuation.

Finally, we used postintervention data to compare the two districts with respect to the distribution of time until discontinuation. The Kaplan-Meier plots of the survival functions for discontinuation showed no difference between the two districts (log-rank p=.09; not shown). Five percent of women in Mumias discontinued by 98 days, $8 \%$ by 196 days and $23 \%$ by 294 days; the proportions in Nyando were $4 \%, 6 \%$ and $16 \%$, respectively.

\section{DISCUSSION}

This study is the first to evaluate a communication campaign to increase contraceptive continuation. The findings indicate that injectable users in the treatment district were exposed to intervention components and that spill-over of campaign-specific print materials into the comparison district was minimal. We found no difference, however, between the two districts in the change in discontinuation rates before and after the intervention. And in analyses of postintervention data, we found no difference between the treatment and comparison districts in time to discontinuation, further suggesting that campaign exposure was not associated with increased continuation.

The main reason for discontinuation in both districts was method-related side effects or health concerns. Interestingly, the association with fear of side effects went in opposite directions in the two districts (and was only marginally significant in Mumias), as did the association with exposure to family planning messaging. Most surprising was the finding that participants in Nyando were more likely to discontinue when they had received information about method-related side effects from providers-a topic that was a primary focus of the campaign. This suggests that telling women about side effects may not be enough to address premature discontinuation. We found no evidence that the variables we included on the basis of the literature were associated with discontinuation; however, there were not enough participants whose marital status changed during the study to reliably estimate that measure's association with discontinuation. As in most previous research, variables related to family planning services were not linked to discontinuation.

Finally, despite the campaign's strong focus on side effects, women's reports of providers supplying such information were more common during the preintervention than the postintervention period. Interestingly, however, women's reports of fear of method-related side effects or health concerns were less common in the postintervention period.

There are several possible reasons why our analyses failed to find evidence that the campaign increased continuation. For example, the influence of side effects, in particular those of the injectable, may be so strong that messages saying "this is normal" cannot compensate. Alternatively, perhaps the campaign's switching message was not prominent enough to encourage participants to switch to another method, or providers' own biases toward the injectable may have made switching difficult for participants. In addition, many women use contraceptives discreetly, and switching to a method that cannot be concealed may not be an option. ${ }^{9}$ Also, unlike adoption behavior, which is a one-time event, continuation behavior occurs over time and may be more difficult to influence with a campaign. And, despite the extensive community involvement in design and implementation, the campaign may not have reached women's partners and other salient referents (from whom we did not collect exposure data), 
or it reached them but did not influence their attitudes and behaviors.

\section{Limitations and Strengths}

This study is not without limitations. We conducted follow-up interviews every three months, or a few days after participants were to receive their next injection should they desire it. Although we reminded women each time that they did not have to continue using a method to remain in the study, we may have influenced continuation by reminding women about their upcoming injections. Thus, the data collection procedures may pose a threat to the study's external validity.

Results from the preintervention period suggest discontinuation rates across districts were different prior to the campaign; however, results of the sensitivity analysis call into question the direction of this difference. The high preintervention loss to follow-up complicates the interpretation of the main research question, because the study was designed to control for differences that existed in discontinuation rates prior to the intervention.

The two districts were not identical preintervention, as their different majority ethnic groups have cultural differences that may influence discontinuation. Our evaluation of the campaign, however, was not based on differences in the discontinuation rates in the treatment and comparison districts postintervention, but on differences in the change over time (pre- to postintervention). Although this difference-in-difference design removes any effects of variables-observed or not-that are constant over the study period (e.g., HIV prevalence rate), it does not take into account effects of unobserved time-variable factors, or unobserved time-stable factors associated with discontinuation that vary over time.

Discontinuation of the injectable is highest right after method initiation. ${ }^{38}$ Unfortunately, we could not track the same individuals before and after the intervention, because women from the preintervention period were no longer first-time users (the primary target audience for the campaign) in the postintervention period. Thus, because we followed communities and not individuals, we cannot rule out the possibility that shifts in community-level discontinuation rates over time might be driven by changes in composition (e.g., migration) rather than exclusively by changes in individual behavior. We must therefore assume that such compositional effects are either nonexistent or consistent across the treatment and comparison districts, which is reasonable given the short time period involved.

We tested for time to discontinuation by fitting pre-and postintervention data from both districts together in two models. The adjusted model allowed us to control for potential confounders that were associated with discontinuation in at least one district during the preintervention period. The disadvantage of the adjusted model, however, is that time-dependent confounding is possible and could dilute the effect of the intervention.

This study has several strengths, most notably its com- prehensive list of independent variables, including some based on theory, and application of factor analysis techniques. A study conducted in Honduras found that contraceptive users' childbearing attitudes vary over time, and identified an association between fertility motivations and contraceptive discontinuation. ${ }^{39}$ Unlike the Honduras study, which measured attitudes at baseline and one year later, the attitudinal factors in this study were measured up to four times over the course of the study. However, we found no association between discontinuation and our attitudinal and motivational variables. The influence of side effects may have been so strong that it was difficult to detect the influence of these variables, or perhaps the items did not accurately measure the intended constructs.

A second strength is the study's prospective longitudinal design combined with its incorporation of time-dependent variables. The advantage of repeated measurements of variables over time is the opportunity to include a measurement of respondents' attitudes and behaviors closer to the time of the event (i.e., discontinuation). This should reduce recall bias and decrease the threat to internal validity.

\section{Conclusions}

The findings from this study can be used to inform interventions designed to increase contraceptive continuation rates in the region and contributes to the body of evidence highlighting the importance of method-related side effects on premature method discontinuation. Clearly, side effects must be addressed more strongly in family planning services, and the development of effective methods with minimal side effects must be prioritized.

\section{REFERENCES}

1. Curtis S and Blanc A, Determinants of contraceptive failure, switching, and discontinuation: an analysis of DHS contraceptive histories, DHS Analytical Reports, Calverton, MD, USA: Macro International, 1997, No. 6

2. Blanc A, Curtis S and Croft T, Does Contraceptive Discontinuation Matter? Quality of Care and Fertility Consequences, Chapel Hill, NC, USA: MEASURE Evaluation, Carolina Population Center, University of North Carolina at Chapel Hill, 1999.

3. Ali M and Cleland J, Contraceptive discontinuation in six developing countries: A cause-specific analysis, International Family Planning Perspectives, 1995, 21(3):92-97.

4. Ali M and Cleland J, Determinants of contraceptive discontinuation in six developing countries, Journal of Biosocial Science, 1999, 31(3):343-360.

5. Piet-Pelon NJ and Rob U, Male involvement in the Bangladesh family planning and reproductive health program, International Quarterly of Community Health Education, 1997, 17(2):195-206.

6. Koenig MA, Hossain MB and Whittaker M, The influence of quality of care upon contraceptive use in rural Bangladesh, Studies in Family Planning, 1997, 28(4):278-289.

7. RamaRao $S$ et al, The link between quality of care and contraceptive use, International Family Planning Perspectives, 2003, 29(2):76-83.

8. Steele F, Curtis SL and Choe M, The impact of family planning service provision on contraceptive-use dynamics in Morocco, Studies in Family Planning, 1999, 30(1):28-42.

9. Kenya National Bureau of Statistics (KNBS) and ICF Macro, Kenya Demographic and Health Survey 2008-2009, Calverton, MD, USA: KNBS and ICF Macro, 2010. 
10. World Health Organization (WHO) and the INFO Project, Johns Hopkins Bloomberg School of Public Health Center for Communication Programs (CCP), Decision-Making Tool for Family Planning Clients and Providers, WHO and the INFO Project: Geneva: WHO and Baltimore, MD, USA, 2005.

11. Chin-Quee DS, Janowitz B and Otterness C, Counseling tools alone do not improve method continuation: further evidence from the decision-making tool for family planning clients and providers in Nicaragua, Contraception, 2007, 76(5):377-382.

12. Lei ZW et al., Effect of pretreatment counseling on discontinuation rates in Chinese women given depo-medroxyprogesterone acetate for contraception, Contraception, 1996, 53(6):357-361.

13. Hubacher D et al., Factors affecting continuation rates of DMPA, Contraception, 1999, 60(6):345-351.

14. Canto De Cetina TE, Canto P and Ordoñez Luna M, Effect of counseling to improve compliance in Mexican women receiving depotmedroxyprogesterone acetate, Contraception, 2001, 63(3):143-146.

15. Halpern V et al., Strategies to improve adherence and acceptability of hormonal methods of contraception, Cochrane Database of Systematic Reviews, 2011, Issue 4, No. CD004317.

16. Westoff $C$ and Bankole A, Mass media and reproductive behavior in Africa, Demographic and Health Surveys Analytical Reports, Calverton, MD, USA: Macro International, 1997, No. 2

17. Westoff $C$ and Rodríguez $G$, The mass media and family planning in Kenya, International Family Planning Perspectives, 1995, 21(1):26-36.

18. Gupta N, Katende C and Bessinger R, Associations of mass media exposure with family planning attitudes and practices in Uganda, Studies in Family Planning, 2003, 34(1):19-31.

19. Bertrand JT et al., Family planning communications and contraceptive use in Guatemala, El Salvador, and Panama, Studies in Family Planning, 1982, 13(6-7):190-199.

20. Piotrow PT et al., Mass media family planning promotion in three Nigerian cities, Studies in Family Planning, 1990, 21(5):265-274.

21. Chen $S$ and Guilkey DK, Determinants of contraceptive method choice in rural Tanzania between 1991 and 1999, Studies in Family Planning, 2003, 34(4):263-276.

22. Jain AK, Fertility reduction and the quality of family planning services, Studies in Family Planning, 1989, 20(1):1-16.

23. Burke HM, Contraceptive continuation in Kenya, unpublished dissertation, Chapel Hill, NC: School of Public Health, University of North Carolina at Chapel Hill, 2010

24. Montaño DE and Kasprzyk D, The theory of reasoned action and theory of planned behavior, in: Glanz K, Rimer BK and Lewis FM, eds., Health Behavior and Health Education: Theory, Research, and Practice, third ed., San Francisco, CA, USA: Jossey-Bass, 2002, pp. 67-98.

25. Fishbein M and Ajzen I, Belief, Attitude, Intention, and Behavior: An Introduction to Theory and Research, Reading, MA: Addison-Wesley, 1975.

26. Zimmerman $\mathrm{M}$ et al., Assessing the acceptability of NORPLANT implants in four countries: findings from focus group research, Studies in Family Planning, 1990, 21(2):92-103.

27. Burke HM and Ambasa-Shisanya C, Qualitative study of reasons for discontinuation of injectable contraceptives among users and salient reference groups in Kenya, African Journal of Reproductive Health, 2011 15(2):67-78

28. Ministry of Health, Kenya, Kenya AIDS Indicators Survey 2007, Nairobi, Kenya: National AIDS/STD Control Program (NASCOP) of the Ministry of Health, Kenya, 2009.

29. Reynolds HW et al., Contraception to prevent HIV-positive births: current contribution and potential cost savings in PEPFAR countries, Sexually Transmitted Infections, 2008, 84(Suppl. 2):ii49-ii53.

30. Reynolds HW et al., The value of contraception to prevent perinatal HIV transmission, Sexually Transmitted Diseases, 2006, 33(6):350-356.

31. Shadish W, Cook T and Campbell D, Experimental and QuasiExperimental Designs for Generalized Causal Inference, Boston, MA, USA: Houghton Mifflin, 2001.

32. WHO, Medical Eligibility Criteria for Contraceptive Use: 2008 Update, Geneva: WHO, 2008
33. Therneau T and Grambsch P, Modeling Survival Data: Extending the Cox Model, New York: Springer Verlag, 2000

34. Fabrigar L et al., Evaluating the use of exploratory factor analysis in psychological research, Psychological Methods, 1999, 4(3):272-299.

35. Thurstone L, Multiple Factor Analysis, Chicago, IL, USA: University of Chicago Press, 1947

36. Rubin D, Multiple Imputation for Nonresponse in Surveys, New York: John Wiley \& Sons, 1987.

37. Collett D, Modelling Survival Data in Medical Research, London: Chapman \& Hall, 1994

38. Polaneczky M et al., Early experience with the contraceptive use of depot medroxyprogesterone acetate in an inner-city clinic population, Family Planning Perspectives, 1996, 28(4):174-178

39. Barden-O'Fallon J et al., Contraceptive Discontinuation: A One-Year Follow-Up Study of Female Reversible Method Users in Urban Honduras, Chapel Hill, NC, USA: MEASURE Evaluation, 2008.

\section{RESUMEN}

Contexto: Las campañas de comunicación pueden usarse para mejorar la continuación del uso de anticonceptivos; sin embargo, solo se han evaluado unas pocas intervenciones dirigidas a reducir la discontinuación de métodos anticonceptivos. Métodos: Se recolectaron datos de muestras independientes de nuevas usuarias de anticonceptivos inyectables en el distrito de Nyando, Kenia-en donde se realizó una campaña de comunicación para aumentar la continuación del uso de anticonceptivos-y en un distrito de comparación, nueve meses antes y nueve meses después de la implementación de la intervención. Se utilizó el análisis de supervivencia para comparar los grupos de intervención y comparación en relación a la distribución del tiempo hasta la primera discontinuación del uso de un método moderno en mujeres que todavía tenían una necesidad de planificación familiar.

Resultados: La exposición a la información sobre planificación familiar fue alta tanto en el distrito de tratamiento como en el de comparación antes (97\% y 85\%, respectivamente) y después de la intervención (99\% y 78\%, respectivamente). Luego de la intervención, el 5\% de las mujeres en el distrito de comparación había discontinuado el método a los 98 días, 8\% a los 196 días y 23\% a los 294 días; las proporciones en el distrito de tratamiento fueron de $4 \%, 6 \%$ y $16 \%$, respectivamente. No se encontró una diferencia significativa entre los distritos en las tasas de continuación del uso de anticonceptivos a los nueve meses posteriores a la intervención. Los efectos secundarios relacionados con el método o las preocupaciones relacionadas con la salud fueron las razones que se asociaron con mayor consistencia a la discontinuación. Otros factores asociados a la discontinuación difirieron entre los distritos.

Conclusiones: El abordaje de los efectos secundarios y las preocupaciones relacionadas con la salud será sumamente importante en el mejoramiento de la continuación en el uso de los métodos inyectables.

\section{RÉSUMÉ}

Contexte: Les campagnes de communication peuvent entrer en jeu dans l'amélioration de la poursuite de la contraception. Peu d'interventions visant à réduire l'arrêt de la contraception ont cependant été évaluées. 
Méthodes: Les données proviennent d'échantillons indépendants de nouvelles utilisatrices de l'injection dans le district kenyan de Nyando (site d'une campagne de communication visant à accroître la poursuite de la contraception) et dans un district de comparaison, neuf mois avant et neuf mois après l'intervention. L'analyse de survie a mis en regard les groupes d'intervention et de comparaison concernant la distribution temporelle jusqu'à l'arrêt initial de la méthode moderne chez les femmes ayant toujours un besoin de planification familiale. Résultats: L'exposition à l'information relative à la planification familiale s'est avérée élevée dans les deux districts, d'intervention et de comparaison, avant (97\% et $85 \%$, respectivement) et après l'intervention (99\% et 78\%, respectivement). Après l'intervention, 5\% des femmes du district de comparaison avaient arrêté la méthode au bout de 98 jours, $8 \%$ au bout de 196 jours et 23\% au bout de 294 jours. Dans le district d'intervention, ces proportions étaient, respectivement, de 4\%, $6 \%$ et $16 \%$. Aucune différence significative n'est observée entre les districts dans les taux de poursuite de la contraception postintervention sur neuf mois. Les effets secondaires ou préoccupations de santé ayant trait à la méthode sont la raison le plus souvent associée à l'arrêt. Les autres facteurs d'arrêt diffèrent selon le district.

Conclusions: Aborder les effets secondaires et les préoccupations de santé sera essentielle à l'amélioration de la poursuite de cette méthode.

\section{Acknowledgment}

This research was made possible through support from the Office of Population and Reproductive Health, Bureau for Global Health, U.S. Agency for International Development (USAID), under the terms of Award GPO-A-00-05-00022-0. The opinions expressed herein are those of the authors and do not necessarily reflect the views of USAID.

Author contact: hburke@fhi360.org 